OPEN ACCESS

Edited by:

Veena Kumari,

Brunel University London,

United Kingdom

Reviewed by:

Meenakshi Shukla,

Magadh University, India

Evangelia Nena,

Democritus University of

Thrace, Greece

*Correspondence:

Xueling Yang

yhtyx12006@126.com

You Wang

wangyoupsy@foxmail.com

tThese authors share first authorship

Specialty section:

This article was submitted to

Mood Disorders,

a section of the journal

Frontiers in Psychiatry

Received: 26 May 2021

Accepted: 25 October 2021

Published: 30 November 2021

Citation:

Yang $C$, Chen P, Xie J, He Y, Wang Y and Yang $X$ (2021) Childhood

Socioeconomic Status and

Depressive Symptoms of Young

Adults: Mediating Role of Childhood

Trauma. Front. Psychiatry 12:706559.

doi: 10.3389/fpsyt.2021.706559

\section{Childhood Socioeconomic Status and Depressive Symptoms of Young Adults: Mediating Role of Childhood Trauma}

\author{
Caiyan Yang ${ }^{1+}$, Peiyi Chen ${ }^{1+}$, Junyi Xie ${ }^{1}$, Yongtong $\mathrm{He}^{1}$, You Wang ${ }^{1,2,3 *}$ and \\ Xueling Yang ${ }^{1,2,3 *}$
}

\begin{abstract}
${ }^{1}$ Department of Psychology, School of Public Health, Southern Medical University, Guangzhou, China, ${ }^{2}$ Department of Psychiatry, Zhujiang Hospital, Southern Medical University, Gaungzhou, China, ${ }^{3}$ Guangdong Provincial Key Laboratory of Tropical Diseases, Southern Medical University, Guangzhou, China
\end{abstract}

Background: Studies have shown that low childhood socioeconomic status (SES) is associated with a high prevalence of depressive symptoms. Childhood trauma, as a potential consequence of low SES, may play an important part, but the mediation effect of childhood trauma remains to be elucidated.

Methods: A cross-sectional survey was conducted among 1,807 university students. The MacArthur Scale of Subjective Social Economic Status-Youth Version, Childhood Trauma Questionnaire, and Beck Depression Inventory were used to measure childhood SES, childhood trauma, and current depressive symptoms, respectively. A structural equation model (SEM) was employed to demonstrate the mediating role of childhood trauma on the association between childhood SES and depressive symptoms.

Results: The SEM demonstrated that childhood SES had significant indirect effects upon depressive symptoms via childhood trauma. Childhood trauma accounted for 89.3\% of the total effect, indicating a profound mediation effect.

Conclusions: The effect of childhood SES on the depressive symptoms of young adults was mediated by childhood trauma, which emphasizes the importance of early prevention and intervention of child neglect/abuse.

Keywords: socioeconomic status, depressive symptoms, childhood trauma, young adults, China

\section{INTRODUCTION}

Studies have demonstrated that socioeconomic status (SES) is associated with the risk of major depressive disorders. One meta-analysis concluded that low SES was associated with an increased risk of depression worldwide [odds ratio $(\mathrm{OR})=1.81,95 \%$ confidence interval (CI) 1.6-2.1] (1).

Consistently, rural residents in China have shown a higher incidence of depression, compared with individuals living in urban areas, with an inverse relationship between family income and depression observed (2). The risk of depression for individuals living in rural areas and with low SES has been shown to be 1.5- and 2.3-fold higher, respectively, than that for individuals living in urban areas (OR 1.5, 95\% CI 1.4-1.7; OR 2.3, 95\% CI 2.1-2.4) (3).

Theories based on social causation and health selection have been proposed to explain the relationship between SES and mental disorders (4). Social causation theory suggests that higher levels of stress and adversity caused by low SES account for the 
observed elevation in the risk of psychological disorders. Health selection theory assumes that mental disturbances interfere with upward mobility or result in downward mobility, which, in turn, influences SES in individuals with mental disorders. While previous research favors social causation theory, evidence from China examining these theories is scarce. Furthermore, psychosocial mechanisms underlying the effect of SES on depression merit additional exploration.

Studies have shown that the effects of SES on mental health vary by the age of experience. For example, childhood SES (which is determined by family economic status) has been found to play a profound role in self-rated health, relative to adulthood SES, and mental disorders are primarily influenced by early-life SES (5). Evidence regarding the amelioration of these effects by SES improvement later in life are mixed, with some research showing that improvement of SES in adulthood may not reduce the adverse effect of childhood SES on adult depression $(6,7)$ and other research showing that the negative influence of childhood SES on adult depression may be buffered by a rise of SES in adulthood, with improvement of SES decreasing the risk of adult depression (8). However, if there is a failure in improvement of adulthood economic status, then the probability of developing depression may be increased (9). These disparate results may be due to a mixture of the effects of childhood SES and adulthood economic status in adult cohorts that were examined in previous studies. As the current study focuses on young adults, it should be noted that, in China, $>90 \%$ of university students are dependent upon their family members for financial support $(10,11)$. The first and second year undergraduate students are selected in this study because their financial resources are mainly from their families as mentioned before, while college students in their third year and above usually start to do part-time jobs and begin to have other financial sources (12). If we choose the third year and above undergraduate college students, their other financial sources will be confounding factors of our research. As a result, we choose the first and second year students to reduce the influence of other financial sources.

Childhood SES has also been shown to be closely related to physical trauma, emotional trauma, and/or sexual abuse during childhood (13). Cross-sectional research has shown that Childhood Trauma Questionnaire (CTQ) scores in high-income countries are relatively low (14), whereas childhood trauma occurs more frequently in low-SES areas (13). A United Nations International Children's Emergency Fund report found a need for national-level data on violence against children in China (15). Similar to SES, childhood trauma has also been shown to be an important risk factor for depression development (16-20). For example, one study exploring the predictors of depressive symptoms in Chinese college students found that a greater childhood abuse was associated with more severe depressive symptoms (OR 1.05, 95\% CI 1.02-1.08) (21). One study published in 2019 revealed that being exposed to socioeconomic adversity added to the possibility of childhood abuse, which, in turn, was associated with worse maternal and child outcomes (22). In addition, a study published in 2021 examining the relationship between family finances at the age of 11 years and affective symptoms in adulthood found that childhood neglect had a mediating role (23). Thus, childhood trauma may act as an intermediate process between childhood SES and adulthood depression. While the abovementioned research adds to the picture of how SES and trauma are related to mental health in adulthood, empirical evidence supporting the mediating role of childhood trauma in the relationship between childhood SES and depression pathogenesis is lacking.

In the present study, we recruited first and second year university students, aged $>18$ years, who did not receive financial support from their families. We aimed to (i) clarify the effect of childhood SES on adulthood depression and (ii) examine the mediation effect of childhood trauma on the relationship between childhood SES and adulthood depression, using a structural equation model (SEM).

\section{METHODS}

\section{Study Design}

This was a cross-sectional study to investigate the relationship among SES, childhood trauma, and depressive symptoms in Chinese undergraduate students.

\section{Ethical Approval of the Study Protocol}

Students provided written informed consent before taking part in our survey. Each step of the study was followed and approved (31800928) by the Ethics Committee of Southern Medical University (Guangdong, China).

\section{Participants}

First and second year undergraduate students from Southern Medical University were recruited using cluster random sampling. Southern Medical University enrolls students from most provinces in China. A total of 1,905 students (aged 16-22 years) completed self-reported questionnaires.

Exclusion criteria were as follows: (i) age $<18$ years, (ii) missed responses for $>10 \%$ of the total items, and (iii) apparently fake responses (e.g., selecting the same value repeatedly). Utilizing these criteria, 98 surveys were excluded from analyses, thereby leaving 1,807 (94.9\%) valid samples. The study cohort comprised 796 males (44.1\%) and 1,011 females (55.9\%), with ages ranging from 18 to 22 years (mean $\pm \mathrm{SD}=20.25 \pm 1.54$ ). There was no significant difference in depressive symptoms $(t=$ $-0.80, p=0.429)$ or scores for childhood trauma $(t=1.47, p=$ 0.142 ) between male and female participants, but childhood SES reported by females $(5.02 \pm 1.32)$ was slightly higher than that for males $(4.89 \pm 1.36, t=-2.06, p=0.041)$.

\section{Procedure}

The survey was conducted by a trained researcher. Participants were asked to complete the questionnaire truthfully. After completing the questionnaire, participants were compensated with course credit.

\section{Measures}

\section{Childhood SES}

Childhood SES was assessed using the MacArthur Scale of Subjective Social Status-Youth Version (MSSSS-YV) (24). This 
measure uses the visual aid of "ladders" to assess family socioeconomic placement in society and personal socioeconomic placement from 1 to 10 (the first "rung" represents the bottom, and the 10th rung represents the top). We chose the first item of the MSSSS-YV and documented childhood SES during four stages (before the age of 6 years, elementary school, middle school, and high school). The mean response from these four items was chosen to represent general childhood SES. Studies have revealed the use of ladder ranking to be more powerful for reflecting the relationship between SES and individual mental health than other traditional objective indicators (25-27). The MSSSS-YV has also shown great reliability in Chinese college students (Cronbach's alpha coefficient: 0.79) (28). In the current study, the Cronbach's alpha coefficient was 0.90 . Ferreira et al. suggested that participants who choose the bottom four ladder rungs (1-4) of the MSSSS-YV should be considered to be from a low-SES family (29).

\section{Childhood Trauma}

Childhood trauma was assessed by the Chinese version of the Childhood Trauma Questionnaire-Short Form (CTQ-SF). This measure was developed by Bernstein and has been used widely to measure various types of childhood maltreatment $(30,31)$. The scale contains 28 items, and each item is scored using a five-point Likert scale ranging from 1 (never) to 5 (always). The CTQ-SF has five subscales: emotional neglect (EN), emotional abuse (EA), physical neglect (PN), physical abuse (PA), and sexual abuse (SA), with each subscale consisting of five items. The cutoff points for severe trauma in the CTQ-SF subscales are as follows: $\mathrm{EN} \geq 15$, $\mathrm{EA} \geq 13, \mathrm{SA} \geq 8, \mathrm{PA} \geq 10$, and $\mathrm{PN} \geq 10(31,32)$. The CTQ-SF has shown good reliability and validity among Chinese college students $(33,34)$, with the Cronbach's alpha coefficient being calculated at 0.86 in the present study.

\section{Depressive Symptoms}

We used the Chinese version of the Beck Depression Inventory Version II (BDI-II; 21 items) to measure depressive symptoms. BDI-II is one of the most frequently used and standardized scales to assess depressive symptoms over the previous 2 weeks in adults. The BDI-II comprises 21 items rated on a four-point scale ranging from 0 (no symptoms) to 3 (severe symptoms). Total scores range from 0 to 63 , with a higher score indicating more severe depressive symptoms. Individuals with BDI-II scores $>$ 13 are considered to have depressive symptoms. The items of BDI-II are divided into three dimensions: emotional symptoms, cognitive symptoms, and somatic symptoms (35). The BDI-II has shown good reliability and validity among Chinese college students $(36,37)$. The Cronbach's alpha coefficient in the current study was 0.88 .

\section{Data Analyses}

Preliminary data analyses were conducted using SPSS 22.0 (IBM, Armonk, NY, USA). Distributions of SES, childhood trauma, and depressive symptoms were slightly skewed. Parametric tests (e.g., two-sample $t$-test) are robust, even for heavily skewed distributions if the sample size is large $(38,39)$. In the current study, the sample size was sufficient. Thus, we first used a twosample $t$-test to examine the effect of sex on SES, childhood trauma, and depressive symptoms. Then, we calculated the prevalence of low childhood SES, depressive symptoms, and each type of childhood trauma. Comparisons of childhood trauma and depressive symptoms between the high-SES and low-SES groups were made using independent sample $t$-tests. A Pearson's correlation was used to reveal the correlation of the three key variables.

An SEM was adopted to test the hypothesis that childhood trauma mediates the relationship between childhood SES and depressive symptoms in adulthood. The SEM was calculated with AMOS 21.0 (IBM) using maximum likelihood estimation. In this model, childhood trauma with five observed variables (EN, EA, PN, PA, and SA) and depressive symptoms with three observed variables (emotional symptoms, cognitive symptoms, and somatic symptoms) were considered "latent" variables, and childhood SES was estimated as an "observed" variable. The standards of goodness-of-fit indices were as follows: normed fit index (NFI) $\geq 0.90$, comparative fit index (CFI) $\geq 0.90$, goodness of fit index (GFI) $\geq 0.90$, Tucker-Lewis index $(T L I) \geq 0.90$, and root mean square error of approximation (RMSEA) $\leq 0.08$ (40). A bootstrapping procedure was used to test the direct and indirect effects of childhood SES upon depressive symptoms.

\section{RESULTS}

\section{Descriptive Statistics and Correlations}

We found that $27.1 \%$ of students $(n=490)$ reported that they had been raised in a low-SES family. Furthermore, $20.8 \%$ of students $(n=375)$ had suffered at least one type of trauma in their childhood. Hence, low childhood SES and childhood trauma appeared to be common among our study cohort.

Physical neglect showed the highest prevalence of all types of childhood trauma $(14.8 \%, n=268)$, followed by emotional neglect $(7.0 \%, n=126)$. Additionally, $4.1 \%$ of participants had experienced sexual abuse while growing up, while $1.8 \%$ suffered physical abuse $(n=33)$. Emotional abuse was the least common type of childhood trauma, with only 30 students (1.7\%) reporting it. Finally, $13.3 \%$ of students $(n=240)$ were screened to have depressive symptoms.

Table 1 shows that undergraduates from low-SES families demonstrated higher scores on the CTQ-SF and BDI-II than those from high-SES families. Specifically, the prevalence of emotional abuse, physical abuse, emotional neglect, and physical neglect was significantly higher in low-SES students. Moreover, affective, cognitive, and somatic symptoms of depression were more severe in low-SES students. Furthermore, participants with at least one type of childhood trauma had more depressive symptoms than those who did not experience at least one type of childhood trauma $(t=10.44, p<0.001)$.

Table 2 shows that childhood SES is negatively correlated with both childhood trauma $(r=-0.15, p<0.001)$ and depressive symptoms $(r=-0.10, p<0.001)$, while a positive correlation between childhood trauma and depressive symptoms $(r=0.34, p$ $<0.001)$ was observed. The five forms of childhood trauma were 
TABLE 1 | Differences between high SES and low SES participants on depressive symptoms and childhood trauma.

\begin{tabular}{lccccc}
\hline Variables & SES $\leq \mathbf{4}(\boldsymbol{n}=\mathbf{4 9 0})$ & SES $>\mathbf{4}(\boldsymbol{n}=\mathbf{1 , 3 1 7})$ & $\boldsymbol{t}$ & $\boldsymbol{P}$ \\
\cline { 2 - 3 } & Mean \pm SD & Mean \pm SD & & \\
\cline { 2 - 3 } & $7.57 \pm 6.95$ & $6.22 \pm 6.29$ & 3.75 & $<0.001$ \\
BDI & $6.36 \pm 1.64$ & $6.06 \pm 1.49$ & 3.52 & $<0.001$ \\
Affective & $9.80 \pm 3.14$ & $9.09 \pm 2.66$ & 4.49 & $<0.001$ \\
Cognitive & $12.41 \pm 3.07$ & $12.08 \pm 2.99$ & 2.07 & 0.039 \\
Somatic & $22.11 \pm 3.99$ & $20.93 \pm 3.65$ & 5.74 & $<0.001$ \\
CTQ-SF & $6.94 \pm 2.29$ & $6.46 \pm 1.79$ & 4.26 & $<0.001$ \\
EA & $5.65 \pm 1.30$ & $5.48 \pm 1.13$ & 2.57 & 0.010 \\
PA & $5.43 \pm 1.04$ & $5.36 \pm 1.12$ & 1.11 & 0.269 \\
SA & $9.28 \pm 3.85$ & $8.33 \pm 3.35$ & 4.85 & $<0.001$ \\
EN & $7.88 \pm 2.58$ & $6.88 \pm 2.17$ & 7.63 & $<0.001$ \\
PN & & & & \\
\hline
\end{tabular}

$B D I$, Beck Depression Inventory; Affective, affective factor of BDI; Cognitive, cognitive factor of BDI; Somatic, somatic factor of BDI; CTQ, Childhood Trauma Questionnaire; EA, emotional abuse subscale of CTQ; PA, physical abuse subscale of CTQ; SA, sexual abuse subscale of CTQ; EN, emotional neglect subscale of CTQ; PN, physical neglect subscale of CTQ; SES, socioeconomic status (as determined using the MacArthur Scale of Subjective Social Status - Youth Version).

also found to be negatively correlated with childhood SES and depressive symptoms.

\section{Mediation Analysis}

We conducted SEM to test the mediating role of childhood trauma on the relationship between childhood SES and depressive symptoms (Figure 1). The hypothetical model fits the data well $\left(n=1,807, \chi^{2} / \mathrm{df}=9.96, \mathrm{NFI}=0.95, \mathrm{CFI}=0.95\right.$, $\mathrm{GFI}=0.97$, TLI $=0.93$, RMSEA $=0.070)$. The standardized path coefficients from SES to childhood trauma $(\beta=-0.21, p$ $<0.001)$ and from childhood trauma to depressive symptoms $(\beta$ $=0.51, p<0.001)$ were significant. The direct influence of SES on depressive symptoms was not significant $(\beta=-0.012, p=$ 0.607 ). The total effect in this model was 0.112 , and the mediating effect was 0.100 , which accounted for $89.3 \%$ of the total effect.

Table 3 shows the detailed effect size of direct and indirect pathways in the mediation model. These results indicate that childhood trauma plays a profound mediating role in the link between childhood SES and depressive symptoms in adulthood. Young adults raised in low-SES families tended to experience more trauma during childhood, and more traumatic experiences in childhood may lead to the development of more depressive symptoms in early adulthood.

\section{DISCUSSION}

First, we investigated associations among childhood SES, childhood trauma, and depressive symptoms in adulthood. Then, we employed an SEM to verify the hypothesis that the effect of childhood SES on depressive symptoms is mediated via childhood trauma.

Like previous studies $(1-3,41)$, the results of the present study demonstrate the link between childhood SES and depressive symptoms in young adults. Young adults from low-SES families exhibited more severe depressive symptoms than those from high-SES families, and depressive symptoms were significantly related to low childhood SES. A recent survey in China that was conducted in a community sample showed that low SES is related to both depressive symptoms and major depressive disorder (3). Therefore, our findings provide further evidence for an important role of childhood SES in the formation of depressive symptoms.

Trauma was a common experience during childhood in the present study: $27.1 \%$ of young adults reported at least one type of trauma. Physical neglect was the most prevalent trauma, followed by emotional neglect, sexual abuse, physical abuse, and emotional abuse. Similar to the current findings, a study conducted in the USA showed neglect to be the most prevalent form of child maltreatment (42). In general, we found that childhood trauma was a risk factor for depressive symptoms in young adults. Among all types of childhood trauma, emotional abuse and emotional neglect were the predominant risk factors associated with depressive symptoms ( $r=0.35$ and $r=0.33$, respectively), followed by physical neglect $(r=0.26)$. Although the prevalence of emotional abuse was $1.7 \%$, the association between emotional abuse and depressive symptoms was the highest. This finding is consistent with a meta-analysis revealing that emotional abuse during childhood showed the highest correlation with depression (43). Thus, childhood emotional abuse is worthy of more attention with respect to depressive symptom prevention. In addition, emotional abuse and emotional neglect showed a modest correlation with each other $(r=0.48)$, and both were closely related to depressive symptoms; therefore, emotional maltreatment, both neglect and abuse, should be granted more attention in research.

As hypothesized, childhood trauma was demonstrated to be associated with childhood SES. Childhood trauma was more likely to occur in low-SES families (Table 2). Physical neglect was the type of trauma with the highest level of relation to SES ( $r=$ $-0.20)$, followed by emotional neglect $(r=-0.16)$, emotional abuse $(r=-0.11)$, physical abuse $(r=-0.08)$, and sexual abuse $(r=-0.05)$. These findings are in accordance with research that found negligence of children to be more common in families with low incomes and in impoverished nations $(14,44)$.

One study from 2018 suggested that physical abuse and environmental stressors (which include economic stress) that occur during childhood should be considered separately. When these two factors were measured individually and analyzed statistically, the power of predicted prevalence of adult depressive symptoms increased (45). The current study indicates that the role of financial stress and physical abuse in the development of depressive symptoms needs to be distinguished. Matthews et al. summarized that harsh family environments (e.g., domestic conflicts and neglect) are more likely to emerge in low-SES families and that there are psychosocial origins to the connection between SES and health (46). Other studies have also indicated that childhood trauma should be recognized as an important factor contributing to the high incidence of depression in periurban settings, which are typically poorer than urban areas (13). The aforementioned studies suggest that the relationship between 
TABLE 2 | Correlations among SES, CTQ-SF, the different forms of CTQ-SF, and BDI $(N=1,807)$.

\begin{tabular}{|c|c|c|c|c|c|c|c|c|}
\hline Variables & $\mathbf{M} \pm \mathrm{SD}$ & SES & CTQ & PA & EA & SA & EN & PN \\
\hline SES & $4.96 \pm 1.34$ & - & - & - & - & - & - & - \\
\hline CTQ & $21.25 \pm 3.78$ & $-0.15^{\star \star}$ & - & - & - & - & - & - \\
\hline EA & $6.59 \pm 1.95$ & $-0.11^{\star *}$ & $0.83^{\star \star}$ & $0.48^{\star *}$ & - & - & - & - \\
\hline SA & $5.38 \pm 1.10$ & $-0.05^{*}$ & $0.55^{\star \star}$ & $0.23^{\star \star}$ & $0.23^{\star \star}$ & - & - & - \\
\hline BDI & $6.59 \pm 6.50$ & $-0.10^{\star \star}$ & $0.34^{\star *}$ & $0.18^{\star \star}$ & $0.35^{\star \star}$ & $0.14^{\star *}$ & $0.33^{\star \star}$ & $0.26^{\star \star}$ \\
\hline
\end{tabular}

BDI, Beck Depression Inventory; CTQ, Childhood Trauma Questionnaire; PA, physical abuse subscale of CTQ; EA, emotional abuse subscale of CTQ; SA, sexual abuse subscale of CTQ; EN, emotional neglect subscale of CTQ; PN, physical neglect subscale of CTQ; SES, socioeconomic status (as determined using the MacArthur Scale of Subjective Social Status-Youth Version).

${ }^{*} p<0.05 ;{ }^{*} p<0.01$.

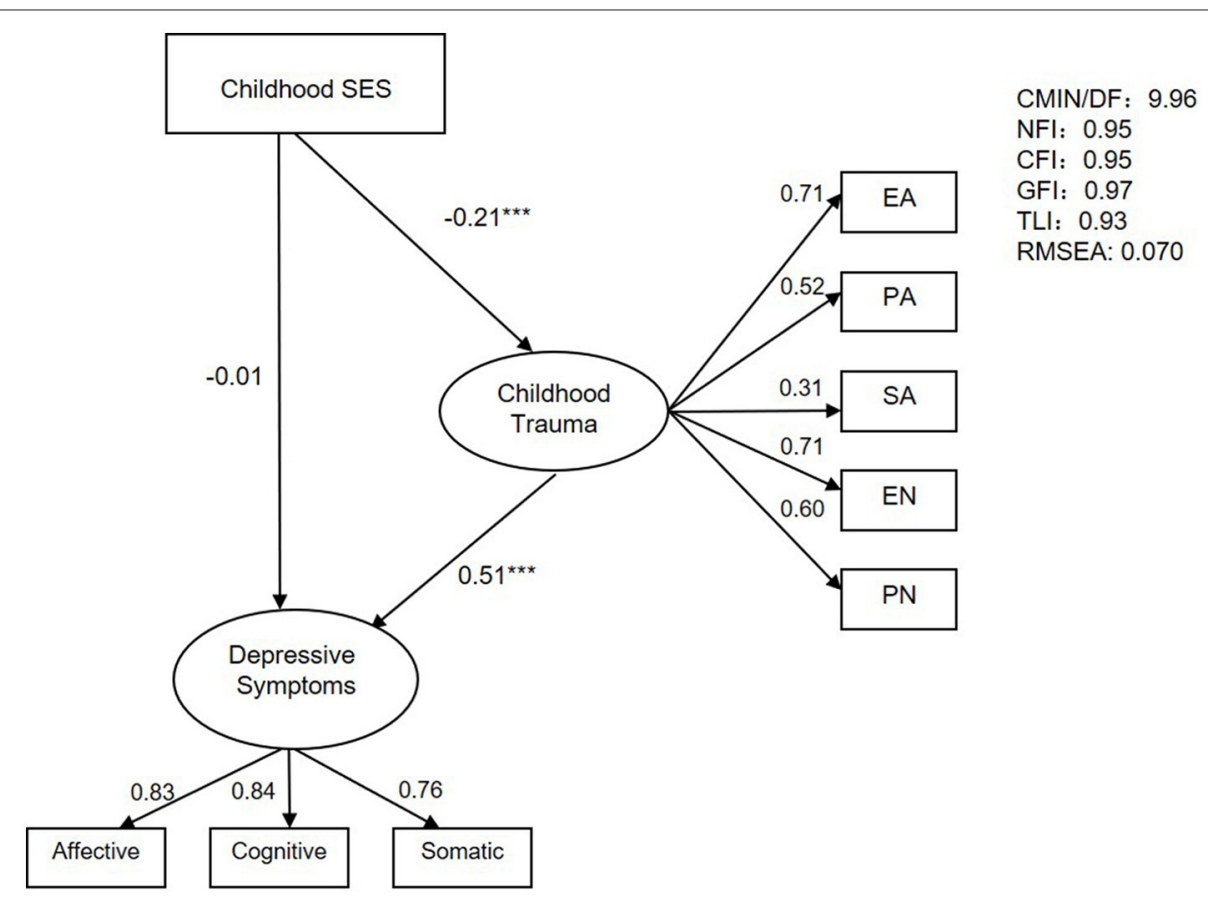

FIGURE 1 | The SEM of the mediating effect of childhood trauma on childhood SES and depressive symptoms. ${ }^{* \star} p<0.001$.

economic stress and depression may be caused by economically related adverse life events. The present study hopes to provide some new insight to better understand the path from childhood SES to childhood trauma and, finally, to the development of depressive symptoms in later life.

The most important contribution of the current study is to examine the potential mediating effect of childhood trauma on childhood SES and adulthood depressive symptoms using an SEM. For theoretical contributions, we directly evaluated the mediating effect of childhood trauma on the link between childhood SES and adulthood depressive symptoms, and the results confirmed our hypothesis. In this study, the mediating effect accounted for $89.3 \%$ of the total effect, indicating that the role of childhood trauma is more important than the direct impact of economic stress on depressive symptoms. A study from 2021 selected two subject groups of different ages, 23 and 50 years old, respectively, and found that childhood neglect played a mediating role between childhood socioeconomic position at 11 years old and current affective symptoms (23). The mediating effect in the 23-year-old population of this study, whose age closely resembled our sample, differed from the current results, at $71.4 \%$. The mediating effect in the present study was relatively high, which may be due to the inclusion of childhood abuse and the use of an SEM. Consistent with the current results, this study also shows that childhood neglect is the core component of mental symptoms caused by economic conditions. Furthermore, the present research also provides a new perspective for the social causation theory. While the social 
TABLE 3 | The analysis of paths and effects $(N=1,807)$.

\begin{tabular}{|c|c|c|c|c|}
\hline \multirow[t]{2}{*}{ Effect } & \multirow[t]{2}{*}{ Path } & \multicolumn{3}{|c|}{ Effect size } \\
\hline & & Estimated & SE & $95 \% \mathrm{Cl}$ \\
\hline Direct & $\begin{array}{l}\mathrm{SES} \rightarrow \text { depressive } \\
\text { symptoms }\end{array}$ & -0.012 & 0.024 & $\begin{array}{c}(-0.048 \text { to } \\
0.032)\end{array}$ \\
\hline \multirow[t]{3}{*}{ Indirect } & $\begin{array}{l}\mathrm{SES} \rightarrow \text { childhood } \\
\text { trauma } \rightarrow \\
\text { depressive } \\
\text { symptoms }\end{array}$ & $-0.100^{\star}$ & 0.015 & $\begin{array}{c}(-0.129 \text { to } \\
-0.080)\end{array}$ \\
\hline & Total effect & 0.112 & & \\
\hline & $\begin{array}{l}\text { Indirect effect (\%, } \\
\text { total indirect } \\
\text { effect/total effect) }\end{array}$ & $0.100(89.3 \%)$ & & \\
\hline
\end{tabular}

${ }^{*} p<0.01$.

causation theory posits that economic stress leads to depression, a review found that increasing income may be a necessary, but not sufficient, condition for the improvement of health in individuals with low incomes (47). The current research provides a new perspective for the improvement of the social causation theory in that it verifies an important mediating variable between earlylife economic stress and later-life depressive symptoms. Our findings also help to emphasize the importance of preventing child maltreatment, in an effort to reduce the prevalence of depressive symptoms observed in low-SES populations in China. In 2017, UNICEF pointed out that China's welfare agencies value financial support more than protection against child abuse (48). The close link between low childhood SES and childhood trauma as well as the profound role of childhood trauma on depressive symptoms observed in the present study, together with the unsatisfactory situation in practice, highlight the need to strengthen child-protection services, while simultaneously providing financial support. While economic adjustment may require long-term effort (49), protection of children can have an immediate impact (50).

\section{Limitations}

Despite the unique contribution to further the understanding of socioeconomic disadvantages, childhood trauma, and their associations with depression, our findings should be interpreted in light of three main limitations. First, we chose the MSSSS-YV to assess subjective SES, without collecting data of the objective financial level, because studies have shown that subjective SES is more closely related to health outcome than objective SES (51). However, objective SES (as indicated by parental employment and family structure) may also contribute to childhood trauma (52). Second, we relied on self-reported measures, which may have attenuated our findings, due to the social desirability effect and recall biases. Third, previous research suggests that current economic status is closely related to depressive symptoms; however, we did not investigate current socioeconomic status. Although the sample of students we recruited in the current study were in a special period, in which they were almost completely financially dependent on the family, is helpful to eliminate the confusion of adult economic status on depression, it also limits the extent of generalizability of the current findings to a wider population.

\section{Future Direction of Research}

The future direction of the current research could aim at refinement of measurement for SES, childhood trauma, and depressive symptoms mentioned here. For instance, assessment of depressive symptoms should be combined with an examiner rating scale and self-rating scale, and a diagnosis from a psychiatrist should be taken into consideration (if necessary). Furthermore, different types of childhood trauma should be subdivided in future research. One study in 2017 showed that suffering multiple traumas was likely to produce various emotional symptoms, so it is necessary to clarify the difference between a single traumatic incident and multiple traumatic incidents in future studies (53). Moreover, researchers should combine prospective and retrospective investigations of childhood trauma to better evaluate the impact of childhood trauma (54).

\section{CONCLUSIONS}

We demonstrated the mediating role of childhood trauma in the correlation between low childhood SES and depressive symptoms in young adulthood. Our data supported the social causation theory, which stresses the causal role of low childhood SES for depressive symptom pathogenesis. Our research also contributes to a deeper understanding of the relationship among childhood SES, trauma, and depressive symptoms later in life.

\section{DATA AVAILABILITY STATEMENT}

The raw data supporting the conclusions of this article will be made available by the authors, without undue reservation.

\section{ETHICS STATEMENT}

The studies involving human participants were reviewed and approved by the Ethics Committee of Southern Medical University. The ethics committee waived the requirement of written informed consent for participation.

\section{AUTHOR CONTRIBUTIONS}

$\mathrm{XY}$ and YW designed the study and the procedure. PC and YH participated in the survey and collected data. CY and PC analyzed the data and wrote the manuscript. JX participated in revising the manuscript. All authors contributed to the article and approved the submitted version. 


\section{FUNDING}

This work was supported by grants from the National Natural Science Foundation of China (Grant Numbers: 31800928 and 71874075), Humanities and Social Science Fund of Ministry of Education of China (Grant Number: 17YJCZH219), the Degree and Postgraduate Education Reform Project of Guangdong Province (Grant Numbers: 2020JGXM024 and 2021JGXM026), and Guangdong Provincial Philosophy and Social Sciences

\section{REFERENCES}

1. Lorant V, Deliège D, Eaton W, Robert A, Philippot P, Ansseau M. Socioeconomic inequalities in depression: a meta-analysis. Am J Epidemiol. (2003) 157:98-112. doi: 10.1093/aje/kwf182

2. Cheng HG, Shidhaye R, Charlson F, Deng F, Lyngdoh T, Chen S, et al. Social correlates of mental, neurological, and substance use disorders in China and India: a review. Lancet Psychiatry. (2016) 3:88299. doi: 10.1016/S2215-0366(16)30166-3

3. Chen Y, Bennett D, Clarke R, Guo Y, Yu C, Bian Z, et al. Patterns and correlates of major depression in Chinese adults: a cross-sectional study of 0.5 million men and women. Psychol Med. (2017) 47:95870. doi: 10.1017/S0033291716002889

4. Dohrenwend BP, Levav I, Shrout PE, Schwartz S, Naveh G, Link BG, et al. Socioeconomic status and psychiatric disorders: the causation-selection issue. Science. (1992) 255:946-52. doi: 10.1126/science.1546291

5. Lindström M, Hansen K, Rosvall M. Economic stress in childhood and adulthood, and self-rated health: a population based study concerning risk accumulation, critical period and social mobility. BMC Public Health. (2012) 12:761. doi: 10.1186/1471-2458-12-761

6. Poulton R, Caspi A, Milne BJ, Thomson WM, Taylor A, Sears MR, et al. Association between children's experience of socioeconomic disadvantage and adult health: a life-course study. Lancet. (2002) 360:1640-5. doi: 10.1016/S0140-6736(02)11602-3

7. Morrissey K, Kinderman P. The impact of childhood socioeconomic status on depression and anxiety in adult life: testing the accumulation, critical period and social mobility hypotheses. SSM Popul Health. (2020) 11:100576. doi: 10.1016/j.ssmph.2020.100576

8. Elovainio $M$, Pulkki-Råback L, Jokela $M$, Kivimäki $M$, Hintsanen $M$, Hintsa $\mathrm{T}$, et al. Socioeconomic status and the development of depressive symptoms from childhood to adulthood: a longitudinal analysis across 27 years of follow-up in the Young Finns study. Soc Sci Med. (2012) 74:9239. doi: 10.1016/j.socscimed.2011.12.017

9. Lorant V, Croux C, Weich S, Deliège D, Mackenbach J, Ansseau M. Depression and socio-economic risk factors: 7-year longitudinal population study. Br J Psychiatry. (2007) 190:293-8. doi: 10.1192/bjp.bp.105.0 20040

10. Jin B, Li J. Does spending self-earned money make college students happier? The effect of source of money on purchase happiness. Curr Psychol. (2021) 1-12. doi: 10.1007/s12144-020-01186-1

11. Luo C. Investigation, analysis and suggestions on the economic status of contemporary college students. Econ Res Guide. (2012) 3:304-6. (in Chinese).

12. Zhang L. Considerations on the problem of college students' taking part-time jobs. J Shanxi Youth Vocat Collage. (2014) 27:38-40. (in Chinese).

13. Hatcher AM, Gibbs A, Jewkes R, McBride RS, Peacock D, Christofides N. Effect of childhood poverty and trauma on adult depressive symptoms among young men in peri-urban south African settlements. J Adolesc Health. (2019) 64:79-85. doi: 10.1016/j.jadohealth.2018.07.026

14. Viola TW, Salum GA, Kluwe-Schiavon B, Sanvicente-Vieira B, Levandowski ML, Grassi-Oliveira R. The influence of geographical and economic factors in estimates of childhood abuse and neglect using the Childhood Trauma Questionnaire: a worldwide meta-regression analysis. Child Abuse Negl. (2016) 51:1-11. doi: 10.1016/j.chiabu.2015. 11.019 13th Five-Year Plan Planning Co-construction Project (Grant Number: GD18XXL04).

\section{ACKNOWLEDGMENTS}

We are indebted to the undergraduates who took time to participate in our study and the research assistants for their contributions to this study.

15. China U. Unicef China 2016-2020: Five Years of Results for Children in China. Unicef China (2021).

16. Mandelli L, Petrelli C, Serretti A. The role of specific early trauma in adult depression: a meta-analysis of published literature. Childhood trauma and adult depression. Eur Psychiatry. (2015) 30:665-80. doi: 10.1016/j.eurpsy.2015.04.007

17. Verdolini N, Attademo L, Agius M, Ferranti L, Moretti P, Quartesan R. Traumatic events in childhood and their association with psychiatric illness in the adult. Psychiatr Danub. (2015) 27(Suppl 1):S60-70. doi: 10.1155/2015/757258

18. Fry D, McCoy A, Swales D. The consequences of maltreatment on children's lives: a systematic review of data from the East Asia and Pacific Region. Trauma Violence Abuse. (2012) 13:209-33. doi: 10.1177/1524838012455873

19. Myers HF, Wyatt GE, Ullman JB, Loeb TB, Chin D, Prause N, et al. Cumulative burden of lifetime adversities: trauma and mental health in low-SES African Americans and Latino/as. Psychol Trauma. (2015) 7:24351. doi: 10.1037/a0039077

20. Piven J, Elison JT, Zylka MJ. Toward a conceptual framework for early brain and behavior development in autism. Mol Psychiatry. (2017) 22:138594. doi: 10.1038/mp.2017.131

21. Liu Y, Zhang N, Bao G, Huang Y, Ji B, Wu Y, et al. Predictors of depressive symptoms in college students: a systematic review and meta-analysis of cohort studies. J Affect Disord. (2019) 244:196-208. doi: 10.1016/j.jad.2018.10.084

22. Anand KJS, Rigdon J, Rovnaghi CR, Qin F, Tembulkar S, Bush N, et al. Measuring socioeconomic adversity in early life. Acta Paediatr. (2019) 108:1267-77. doi: 10.1111/apa.14715

23. Mawson A, Gaysina D. Childhood socio-economic position and affective symptoms in adulthood: the role of neglect. J Affect Disord. (2021) 286:26774. doi: 10.1016/j.jad.2021.03.007

24. Goodman E, Adler NE, Kawachi I, Frazier AL, Huang B, Colditz GA. Adolescents' perceptions of social status: development and evaluation of a new indicator. Pediatrics. (2001) 108:E31. doi: 10.1542/peds.108.2.e31

25. Goldman N, Cornman JC, Chang MC. Measuring subjective social status: a case study of older Taiwanese. J Cross Cult Gerontol. (2006) 21:7189. doi: 10.1007/s10823-006-9020-4

26. Adler NE, Epel ES, Castellazzo G, Ickovics JR. Relationship of subjective and objective social status with psychological and physiological functioning: preliminary data in healthy white women. Health Psychol. (2000) 19:58692. doi: 10.1037/0278-6133.19.6.586

27. Ostrove JM, Adler NE, Kuppermann M, Washington AE. Objective and subjective assessments of socioeconomic status and their relationship to selfrated health in an ethnically diverse sample of pregnant women. Health Psychol. (2000) 19:613-8. doi: 10.1037/0278-6133.19.6.613

28. Bai X, Jiang L, Zhang Q, Wu T, Wang S, Zeng X, et al. Subjective family socioeconomic status and peer relationships: mediating roles of self-esteem and perceived stress. Front Psychiatry. (2021) 12:634976. doi: 10.3389/fpsyt.2021.634976

29. Ferreira WA, Camelo L, Viana MC, Giatti L, Barreto SM. Is subjective social status a summary of life-course socioeconomic position? Cad Saude Publica. (2018) 34:e00024317. doi: 10.1590/0102-311x00024317

30. Bernstein DP, Stein JA, Newcomb MD, Walker E, Pogge D, Ahluvalia $\mathrm{T}$, et al. Development and validation of a brief screening version of the Childhood Trauma Questionnaire. Child Abuse Negl. (2003) 27:16990. doi: 10.1016/S0145-2134(02)00541-0 
31. Spinhoven P, Penninx BW, Hickendorff M, van Hemert AM, Bernstein DP, Elzinga BM. Childhood Trauma Questionnaire: factor structure, measurement invariance, and validity across emotional disorders. Psychol Assess. (2014) 26:717-29. doi: 10.1037/pas0000002

32. Ji S, Wang H. A study of the relationship between adverse childhood experiences, life events, and executive function among college students in China. Psicol Reflex Crit. (2018) 31:28. doi: 10.1186/s41155-018-0107-y

33. He J, Zhong X, Gao Y, Xiong G, Yao S. Psychometric properties of the Chinese version of the Childhood Trauma Questionnaire-Short Form (CTQ-SF) among undergraduates and depressive patients. Child Abuse Negl. (2019) 91:102-8. doi: 10.1016/j.chiabu.2019.03.009

34. Xingfu Z, Yalin Z, Longfei L, Yunfei Z, Hezhan L, Shichang L. Evaluation on reliability and validity of Chinese version of childhood trauma questionnaire. Chin J Clin Rehabil. (2005) 9:105-7.

35. Vanheule S, Desmet M, Groenvynck H, Rosseel Y, Fontaine J. The factor structure of the Beck Depression Inventory-II: an evaluation. Assessment. (2008) 15:177-87. doi: 10.1177/1073191107311261

36. Wang J, He X, Chen Y, Lin C. Association between childhood trauma and depression: a moderated mediation analysis among normative Chinese college students. J Affect Disord. (2020) 276:519-24. doi: 10.1016/j.jad.2020.07.051

37. Kang Y, Liu S, Yang L, Xu B, Lin L, Xie L, et al. Testing the bidirectional associations of mobile phone addiction behaviors with mental distress, sleep disturbances, and sleep patterns: a one-year prospective study among chinese college students. Front Psychiatry. (2020) 11:634. doi: 10.3389/fpsyt.2020.00634

38. Fagerland MW. t-tests, non-parametric tests, and large studiesa paradox of statistical practice? BMC Med Res Methodol. (2012) 12:78. doi: 10.1186/1471-2288-12-78

39. Skovlund E, Fenstad GU. Should we always choose a nonparametric test when comparing two apparently nonnormal distributions? J Clin Epidemiol. (2001) 54:86-92. doi: 10.1016/S0895-4356(00)00264-X

40. Bentler PM. Comparative fit indexes in structural models. Psychol Bull. (1990) 107:238-46. doi: 10.1037/0033-2909.107.2.238

41. Dhamayanti M, Noviandhari A, Masdiani N, Pandia V, Sekarwana N. The association of depression with child abuse among Indonesian adolescents. BMC Pediatr. (2020) 20:313. doi: 10.1186/s12887-020-02218-2

42. Kim H, Wildeman C, Jonson-Reid M, Drake B. Lifetime prevalence of investigating child maltreatment among US children. Am J Public Health. (2017) 107:274-80. doi: 10.2105/AJPH.2016.303545

43. Infurna MR, Reichl C, Parzer P, Schimmenti A, Bifulco A, Kaess M. Associations between depression and specific childhood experiences of abuse and neglect: a meta-analysis. J Affect Disord. (2016) 190:4755. doi: 10.1016/j.jad.2015.09.006

44. Turner HA, Vanderminden J, Finkelhor D, Hamby S. Child neglect and the broader context of child victimization. Child Maltreat. (2019) 24:26574. doi: $10.1177 / 1077559518825312$

45. Sousa C, Mason WA, Herrenkohl TI, Prince D, Herrenkohl RC, Russo MJ. Direct and indirect effects of child abuse and environmental stress: a lifecourse perspective on adversity and depressive symptoms. Am J Orthopsychiatry. (2018) 88:180-8. doi: 10.1037/ort0000283

46. Matthews KA, Gallo LC, Taylor SE. Are psychosocial factors mediators of socioeconomic status and health connections? A progress report and blueprint for the future. Ann N Y Acad Sci. (2010) 1186:14673. doi: 10.1111/j.1749-6632.2009.05332.x

47. Ludbrook A, Porter K. Do interventions to increase income improve the health of the poor in developed economies and are such policies cost effective? Appl Health Econ Health Policy. (2004) 3:115-20. doi: 10.2165/00148365-200403020-00008

48. UNICEF. UNICEF Annual Report 2017 China. UNICEF (2017). Available online at: https://www.unicef.org/reports/unicef-annual-report-2017

49. Hensher M, Tisdell J, Canny B, Zimitat C. Health care and the future of economic growth: exploring alternative perspectives. Health Econ Policy Law. (2020) 15:419-39. doi: 10.1017/S17441331190 00276

50. van der Put CE, Assink M, Gubbels J, Boekhout van Solinge NF. Identifying effective components of child maltreatment interventions: a meta-analysis. Clin Child Fam Psychol Rev. (2018) 21:171-202. doi: 10.1007/s10567-0170250-5

51. Wilkinson LR. Financial strain and mental health among older adults during the great recession. J Gerontol B Psychol Sci Soc Sci. (2016) 71:74554. doi: 10.1093/geronb/gbw001

52. Sedlak AJ, Mettenburg J, Basena M, Petta I, McPherson K, Greene A, et al. Fourth National Incidence Study of Child Abuse and Neglect (NIS-4): Report to Congress. Washington, DC: U.S. Department of Health and Human Services, Administration for Children and Families (2010).

53. Mossige S, Huang L. Poly-victimization in a Norwegian adolescent population: prevalence, social and psychological profile, and detrimental effects. PLoS ONE. (2017) 12:e0189637. doi: 10.1371/journal.pone.01 89637

54. Latham RM, Quilter E, Arseneault L, Danese A, Moffitt TE, Newbury JB, et al. Childhood maltreatment and poor functional outcomes at the transition to adulthood: a comparison of prospective informantand retrospective self-reports of maltreatment. Soc Psychiatry Psychiatr Epidemiol. (2021) 56:1161-73. doi: 10.1007/s00127-020-0 1926-5

Conflict of Interest: The authors declare that the research was conducted in the absence of any commercial or financial relationships that could be construed as a potential conflict of interest.

Publisher's Note: All claims expressed in this article are solely those of the authors and do not necessarily represent those of their affiliated organizations, or those of the publisher, the editors and the reviewers. Any product that may be evaluated in this article, or claim that may be made by its manufacturer, is not guaranteed or endorsed by the publisher.

Copyright (c) 2021 Yang, Chen, Xie, He, Wang and Yang. This is an open-access article distributed under the terms of the Creative Commons Attribution License (CC $B Y)$. The use, distribution or reproduction in other forums is permitted, provided the original author(s) and the copyright owner(s) are credited and that the original publication in this journal is cited, in accordance with accepted academic practice. No use, distribution or reproduction is permitted which does not comply with these terms. 